\title{
EXPERIMENTAL INVESTIGATION OF PRESSURE DROP CHARACTERISTICS ACROSS RECTANGULAR CHANNEL USING DETACHED RIBS
}

\author{
Abdul Rahman ${ }^{1}$, Anandkumar S Malipatil ${ }^{2}$ \\ ${ }^{I}$ P.G.Student, Thermal Power Engineering, VTU, Ro/PG, Kalaburagi, India \\ ${ }^{2}$ Assistant Professor, Thermal Power Engineering, VTU, Ro/PG, Kalaburagi, India
}

\begin{abstract}
In the present day it is very necessary to find heat transfer characteristics of heat exchanger, heat exchanger as an important appliances widely used in day to day life, like in industry, home appliances, gas turbine, transportation, power production, in aircraft etc. the improvement of heat transfer performance of heat exchanger can be done by using insertion of vortex generators across rectangular channel. The experimental study is conducted to examine the pressure drop characteristics across rectangular duct with different geometrical configuration of detached ribs, Detached Ribs as vortex generators are inserted $90^{\circ}$ in a rectangular duct having different aspect ratio $(A R)$ of 1.4,1.8, 3,3.6. The effect of width, pitch ratio (P/H) of inserting vortex generator, flow direction and aspect ratio of duct are examined for Reynolds numbers (Re) based on hydraulic diameter of rectangular duct $D_{h}$, and it is in the range of 8000 to 24000. The results shows if pitch to height increases friction factor ratio decreases by $28.98 \%$, if Reynolds number increases, $8.34 \%$ time friction factor ratio increases , if aspect ratio increases friction factor ratio decrease by $80.03 \%$. The experiment is repeated for different AR of vortex generators 1.4,1.8, 3,3.6. pitch ratio $(P / h)$, width $16.07 \mathrm{~mm}, 12.5 \mathrm{~mm}, 7.5 \mathrm{~mm}, 6.25 \mathrm{~mm}$, for different Re =8000, 12000, 16000, 20000, 24000.
\end{abstract}

Keywords: Rectangular Duct, Detached Ribs, Pressure Drop, Vortex Generator, Aspect Ratio, Friction Factor Ratio

\section{INTRODUCTION}

Heat exchangers are used in almost all the industrial plants, transfer of hot fluid to cold and vice versa, use of heat exchanger is there from olden days to till date and it will be continued, the principle is same from olden days to till today but there are changes in the use of techniques. and in future for better heat transfer enhancement and to improve pressure drop vortex generators as an obstacle in heat exchanger will be used. Most industrial engineers and researchers focus on investigating the heat exchangers because of their wide use in industry, channel flow has got more importance in engineering industry because of their application, the channels may be rectangular, square, triangular, circular, non circular, trapezoid, and polygonal. In this paper, we are using rectangular channel to achieve effective cooling and more compactness, detached ribs are used as vortex generators, the experimental result for detached ribs for different configurations are shown, the influence of pitch to height ratio, aspect ratio of vortex generator for different Reynolds number and pressure are discussed.

K. Yongsiri, p .Eeiamsa-ard, k. wongchare, S. eiamsa-ard (2013): In this paper researcher have taken the incline detached-ribs with different angle of attacks $(\theta) 0^{\circ}, 15^{\circ}, 30^{\circ}$, $45^{\circ}, 60^{\circ}, 75^{\circ}, 105^{\circ}, 120^{\circ}, 135^{\circ}, 150^{\circ}, 165^{\circ}$ with different Reynolds range from 4000 to 24000 for heat transfer, pressure loss, thermal performance and compare with the attached ribs of $\theta=90^{\circ}$. In CFD results at inclined ribs at $\theta$ $=60^{\circ}$ and $120^{\circ}$ heat transfer, thermal performance factors are high than the other inclined ribs. In flow structure and temperature field for Reynolds number 4000, inclined detached ribs of angles $45^{\circ}, 60^{\circ}, 75^{\circ}, 90^{\circ}, 105^{\circ}, 120^{\circ}, 135^{\circ}$ $150^{\circ}$ create more recirculation zone after the ribs and also at the angles $0^{\circ}, 15^{\circ}, 30^{\circ}$ and $165^{\circ}$ we can't find recirculation zone, result include that medium angle of attack give better mixing of fluid.AmnartBoonloi(2014): Researcher use the $30^{\circ} \mathrm{V}$-shaped baffles as the vortex generator placed on the double side of the thin with plate and without plate to perform heat transfer and thermal performance in a square duct, here $30^{\circ} \mathrm{V}$-shaped vortex generator are inserted diagonal to the square for different Reynolds number based on the hydraulic diameter square duct $\mathrm{D}_{\mathrm{h}}$, he find effect of the flow direction (V-Downstream and V-Upstream), pitch ratio, blockage ratio .G.V.Phadtare, Dr.A.A.Pawar, Dr.S.L.Brose, and S.V.channapattana(2013): They used vortex generator of preformatted aluminum plate with thickness $7 \mathrm{~mm}$ and different dimensions of $3 \mathrm{~mm} \mathrm{X} 3 \mathrm{~mm}$, $5 \mathrm{~mm}$ X 5mm, $7 \mathrm{~mm}$ X $7 \mathrm{~mm}$, upstream and downstream for various Reynolds number between 45000 to 80000 with aspect ratio 1 . Here they made test section with wooden they examined thermal and hydraulic action were investigate experimentally for the stationary square $180^{\circ}$ degree bend change. In this experiment they find heat transfer coefficient of the winglet vortex generator might have 108 times higher than the smooth tip. They examined that if with Reynolds number than Nusselt number also increases for both upstream and downstream. For heat transfer upstream shows good results than downstream for different shapes of vortex generator. Plate $7 \mathrm{~mm} \times 7 \mathrm{~mm}$ vortex generator produces good heat transfer than the other two shapes of 
vortex generator. Yinxiozhan, Tae seon park (2012): In this experiment the study is to illustrate the effect of tilt angle of oblique plate for heat transfer and pressure drop for different Reynolds number $\mathrm{Re}=200,600$, the tilt angle ranges from $50^{\circ}-130^{\circ}$. This experiment is conducted on computational and shows that pressure drop and heat transfer heavily depends in tilt angle and Reynolds number. When the angle near the $90^{\circ}-100^{\circ}$ the wall heat transfer is more. In this experiment the vortex generator is attached to the upper wall of channel through glue and studied by using finite volume method. In steady state the effect of tilt angle for pressure drop and heat transfer is not explicit, but when in unsteady state the tilt angle give affect noticeable on the heat transfer and pressure drop, when tilt angle $\alpha=90^{\circ}, 100^{\circ}$ it give better mixing of thermal and wall heat transfer

\section{EXPERIMENTAL SETUP}

The experimental model is as shown in fig .1 the test section consists of rectangular duct with dimension $30 \mathrm{~mm} \times 30 \mathrm{~mm}$ x $900 \mathrm{~mm}$. This test section is made up of Acrylic sheet having thickness $8 \mathrm{~mm}$, and two pressure taps were fitted for measurement of pressure drop across the test section, to this pressure taps micro manometer is connected through the transparent and flexible pipe, Venturimeter and test section are connected through PVC pipe of diameter $30 \mathrm{~mm}$, in Venturimeter two pressure taps are connected to U-tube manometer through transparent and flexible pipe. Inside the test section detached ribs as vortex generator are fixed on to bottom surface with adhesive. The distance between two pressure taps is $850 \mathrm{~mm}$ and between the pressure taps the vortex generators are fixed, gate valve is connected through PVC pipe to test section and then gate valve to blower is connected by flexible pipe of diameter $32 \mathrm{~mm}$

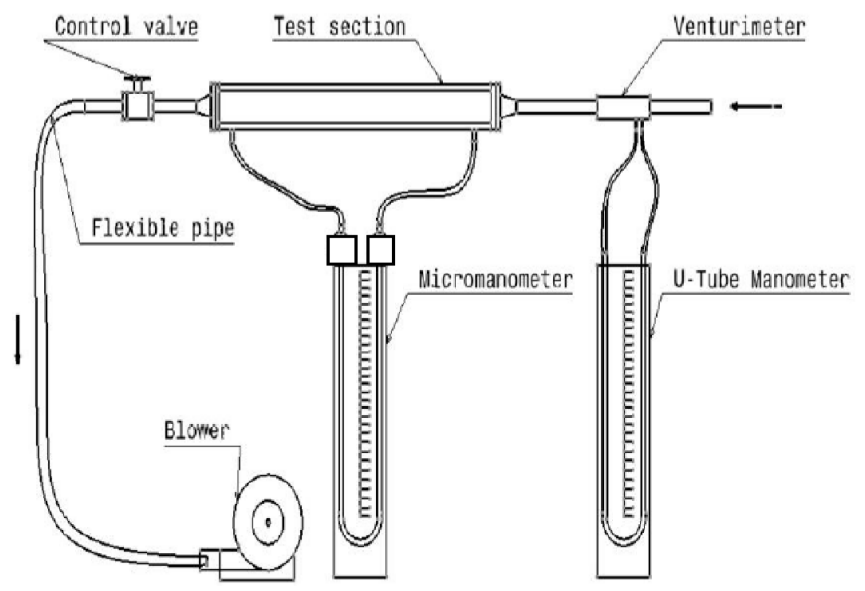

Fig. 1: Experimental setup

In this experiment blower sucks air from atmosphere and that air enters the Venturimeter, when air passes through Venturimeter there will be pressure difference in U-tube manometer and then air passes through the test section causing pressure drop in micro manometer, in this test section pressure drop occur due to friction, surface area. Air passing into Venturimeter and test section is controlled by gate valve, we fix the Reynolds number by controlling air through gate valve, the readings in U-tube manometer and then in the micro manometer are noted down. Same procedure is continued for different Reynolds number for different geometrical configuration of vortex generator and the readings are noted down from micro manometer.

\subsection{Detached Ribs as Vortex Generator}

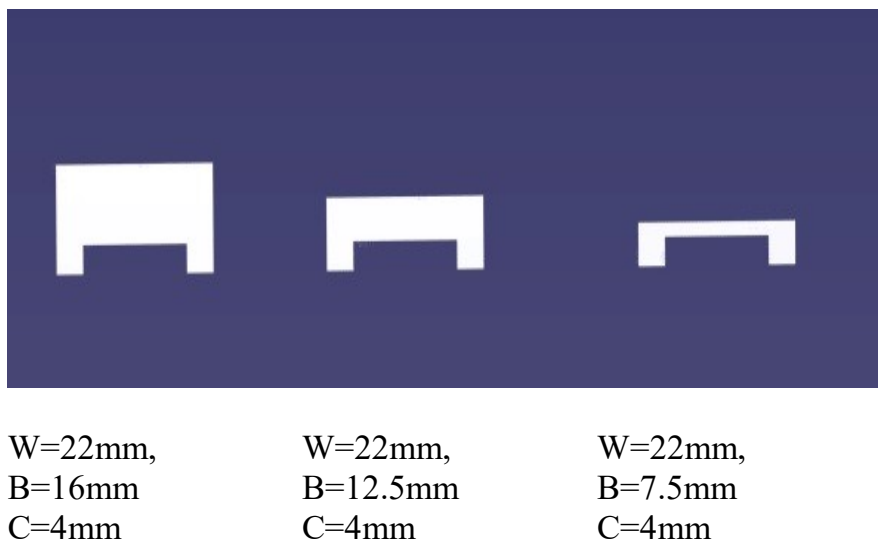

Fig. 2: Different heights of detached ribs

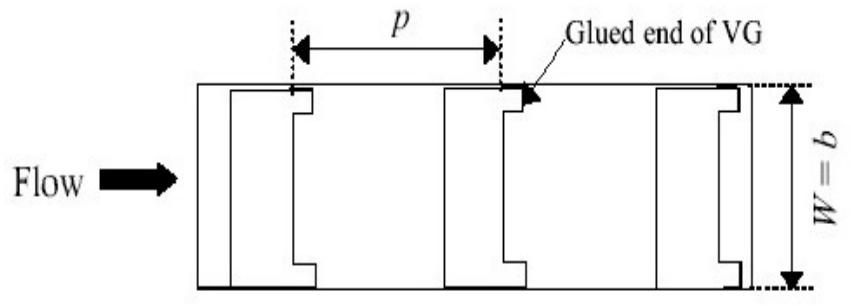

Fig. 3: Arrangement of detached ribs

\section{DATA COLLECTION AND ANALYSIS}

In the present work

Height of Gap for detachment of ribs from base $C=4 \mathrm{~mm}$. Actual discharge $\left(Q_{\text {act }}\right)$ is calculated: $Q_{\text {act }}=V / \mathrm{t} \mathrm{m}^{3} / \mathrm{s}$

Theoretical discharge $\left(\mathrm{Q}_{\mathrm{th}}\right)$ is given by the formula;

$Q_{\text {th }}=\frac{a_{1} \times a_{2} x \sqrt{2 g H}}{a_{1}^{2}-a_{2}^{2}} m^{3} / s$

The coefficient of discharge is give by the formula:

$\mathrm{C}_{\mathrm{d}}=\mathrm{Q}_{\mathrm{act}} / \mathrm{Q}_{\mathrm{th}}$ Reynolds number is given by the formula:

$$
\begin{aligned}
& \mathrm{Re}=\frac{\mathrm{vX} \rho \mathrm{W} \times \mathrm{d}_{1}}{\mu} \\
& \mathrm{v}=\frac{\mathrm{Qact}}{\mathrm{Q}_{1}} \mathrm{~m}^{3} / \mathrm{s}
\end{aligned}
$$

$\rho \mathrm{w}=$ density of water $=1000 \mathrm{Kg} / \mathrm{m}^{3}$ 
$\mu=\quad$ dynamic viscosity of water $8.9 \times 10^{-4} \mathrm{Ns} / \mathrm{m}^{2}$

A micro manometer is connected across the square duct in order to measure the pressure drop in duct. The pressure is given by

$$
p_{x}-p_{y}=2 h g \rho 2\left[1-\frac{\rho_{1}}{\rho_{2}}\left(1-\frac{a}{A}\right)+\frac{\rho}{\rho_{2}} \frac{a}{A}\right]
$$

Actual frictional factor based on pressure drop across the duct is given by

$$
\mathrm{ff}_{\mathrm{a}}=\frac{\Delta \mathrm{p}}{\frac{4 \mathrm{~L}}{\mathrm{Dh}} \frac{\rho v^{2}}{2}}
$$

According to Blasius the friction factor in smooth channel $\left(10^{4}<\operatorname{Re}<10^{6}\right)$ for turbulent flow is given by

$$
f f_{t}=0.046 R e^{-0.2}
$$

\section{RESULT AND DISCUSSION}

\subsection{Variation of Pitch-To-Height $(\mathrm{p} / \mathrm{h})$ with Friction}

\section{Factor Ratio (f/fs)}

Fig. 4 to 7 shows variation of pitch on friction factor ratio (f/fs) with different Reynolds number for detached ribs having different Aspect ratio $\mathrm{AR}=1.4,1.8,3,3.6$ and different width $\mathrm{h}=16,12.5,7.5,6 \mathrm{~mm}$ in a rectangular channel .If pitch-to-height $(\mathrm{p} / \mathrm{h})$ increases than friction factor ratio (f/fs) will decrease as shown in fig 4 to 7 . If small pitch-to-height $(\mathrm{p} / \mathrm{h})$ gives smaller axial distance, it means distance between vortex generator are very small for this reason when air passes to obstruction in the channel for this reason we get high friction factor ratio and high pressure drop, due to high friction factor ratio there will be increasing in mixing of flow and also increase in pressure drop. When height of vortex generator increases friction factor ratio value also increases and increase in pressure drop in fig 7 . In fig 4 we compare higher friction factor ratio for pitch-toheight 16 and 8 , we found that higher value pitch to height at $(\mathrm{p} / \mathrm{h}) 16$ is $37.42 \%$ time less than the friction factor ratio $(\mathrm{f} / \mathrm{fs})$ at lower value pitch to height at $(\mathrm{p} / \mathrm{h}) 4$ and from $(\mathrm{p} / \mathrm{h})$ 4 to $(\mathrm{p} / \mathrm{h}) 8$ friction factor reduces to 0 due to break down of vortices for Reynolds number 24000.In fig 5 we take pitch to height ratio 8 and 16 for Reynolds number 24000 , because for $\mathrm{p} / \mathrm{h}=4$ friction factor ratio is out of range for Reynolds number 24000, higher value pitch to height at (p/h) 16 is $41.40 \%$ less than the lower value pitch to height at $(\mathrm{p} / \mathrm{h})$ 8.In fig 6 we take pitch-to-height ratio12 and 16 for Reynolds number 16000, because for Reynolds number24000 and 20000 and also for pitch-to-height4and 8 is out of range, higher value pitch to height at $(\mathrm{p} / \mathrm{h}) 16$ is $32.12 \%$ less than the lower value pitch to height at $(\mathrm{p} / \mathrm{h}) 12$.

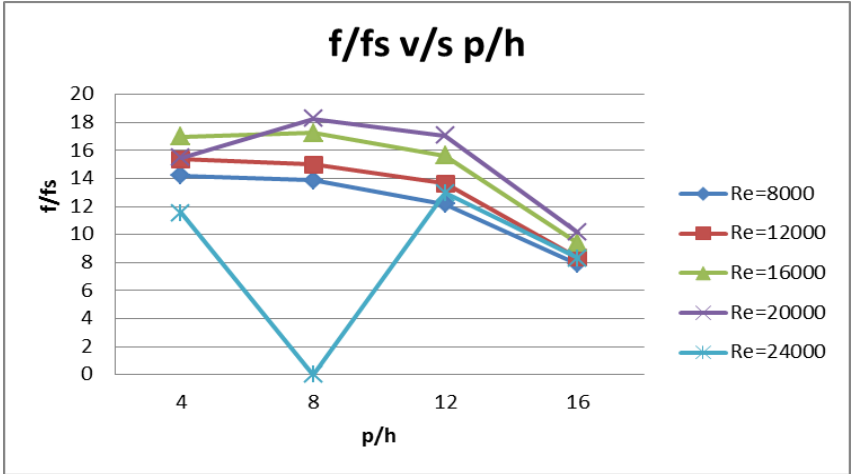

Fig. 4: variation of $\mathrm{f} / \mathrm{fs}$ with $\mathrm{p} / \mathrm{h}(\mathrm{AR}=1.4, \mathrm{~h}=16 \mathrm{~mm})$, Detachment $=4 \mathrm{~mm}$

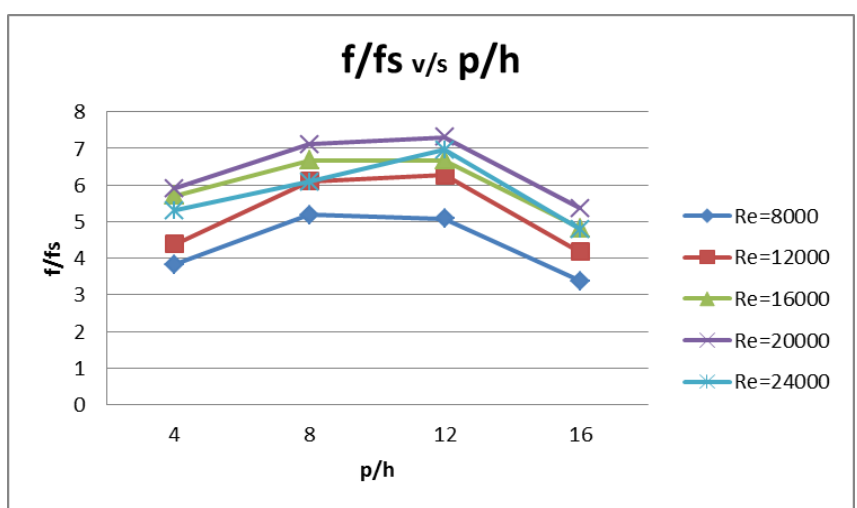

Fig. 5 :Variation of $\mathrm{f} / \mathrm{fs}$ with $\mathrm{p} / \mathrm{h}(\mathrm{AR}=1.8, \mathrm{~h}=12.5 \mathrm{~mm})$, Detachment $=4 \mathrm{~mm}$

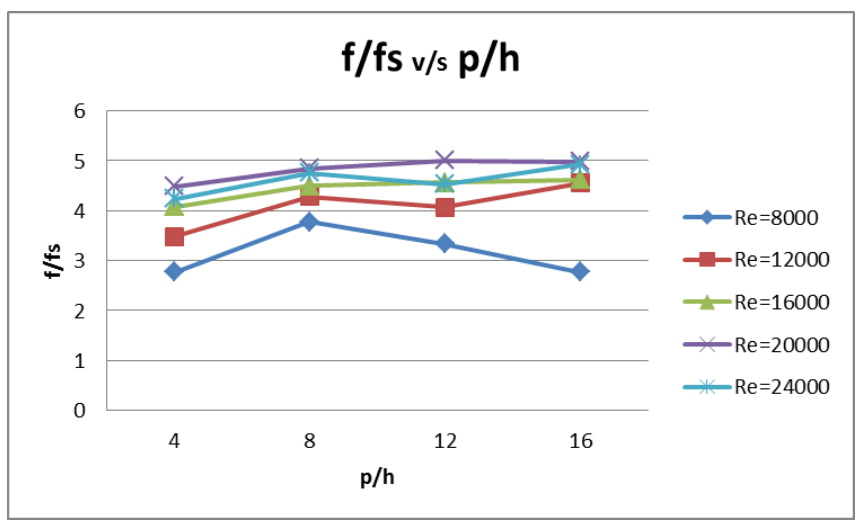

Fig 6: Variation of $\mathrm{f} / \mathrm{fs}$ with $\mathrm{p} / \mathrm{h}(\mathrm{AR}=3, \mathrm{~h}=7.5 \mathrm{~mm})$, Detachment $=4 \mathrm{~mm}$

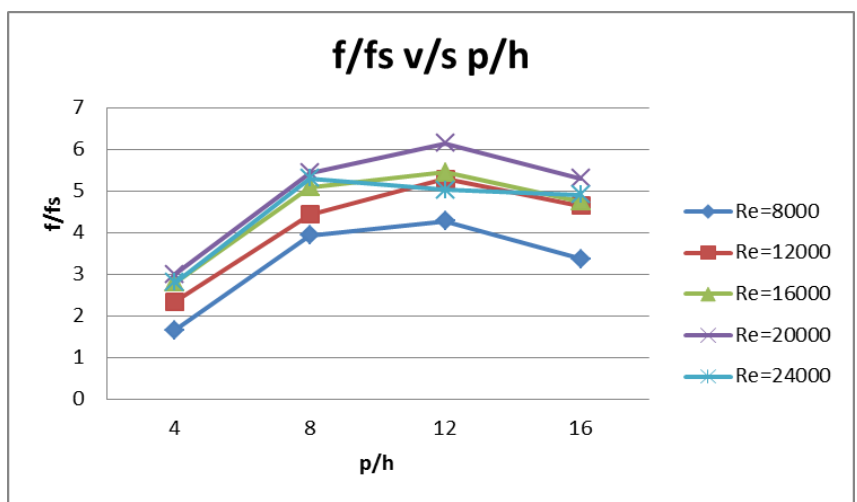

Fig 7: Variation of $\mathrm{f} / \mathrm{fs}$ with $\mathrm{p} / \mathrm{h}(\mathrm{AR}=3.6, \mathrm{~h}=6 \mathrm{~mm})$, Detachment $=4 \mathrm{~mm}$ 


\subsection{Variation of Reynolds Number (Re) with Friction Factor Ratio (f/fs)}

Fig.8 to 11 shows the variation of Reynolds number $(\mathrm{Re})$ with friction factor for pitch to height $(\mathrm{p} / \mathrm{h})$ for detached ribs having different aspect ratio (AR) 1.4,1.8,3,3.6 in a rectangular channel. Comparing all the graphs from fig 8 to 11 we can see only small friction factor ratio variation from all graphs. If Reynolds number increases friction factor ratio also increases, if fluid velocity increases than Reynolds number (Re) also increases and automatically friction factor ratio also increases.

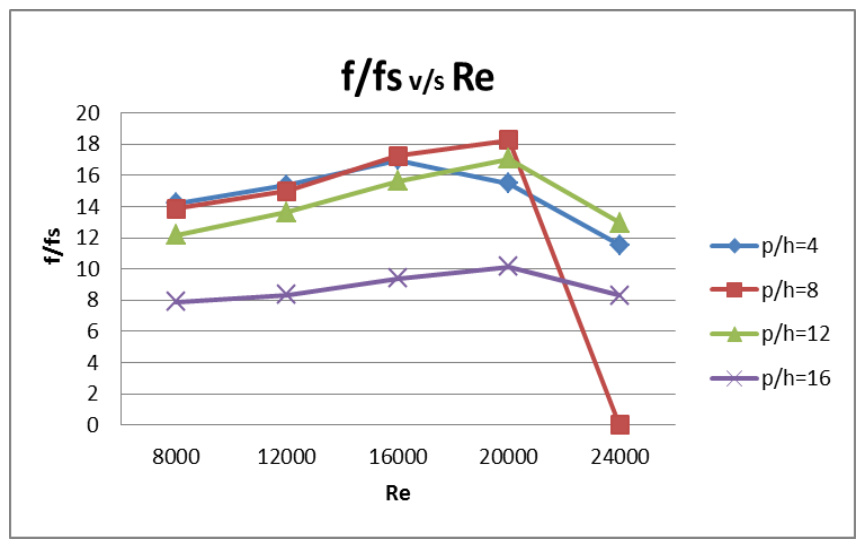

Fig 8: Variation of $\mathrm{f} / \mathrm{fs}$ with $\operatorname{Re}(\mathrm{AR}=1.4, \mathrm{~h}=16 \mathrm{~mm})$, Detachment $=4 \mathrm{~mm}$

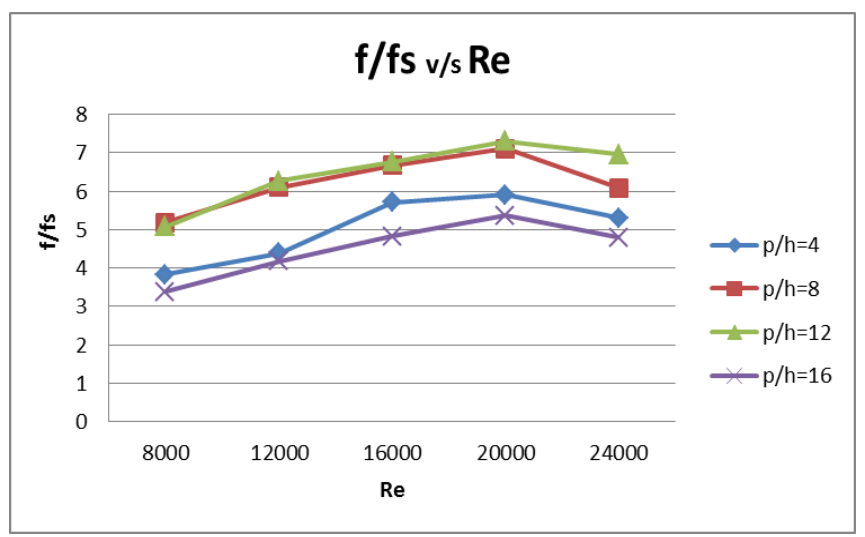

Fig 9: Variation of $\mathrm{f} / \mathrm{fs}$ with $\operatorname{Re}(\mathrm{AR}=1.8, \mathrm{~h}=12.5 \mathrm{~mm})$, Detachment $=4 \mathrm{~mm}$

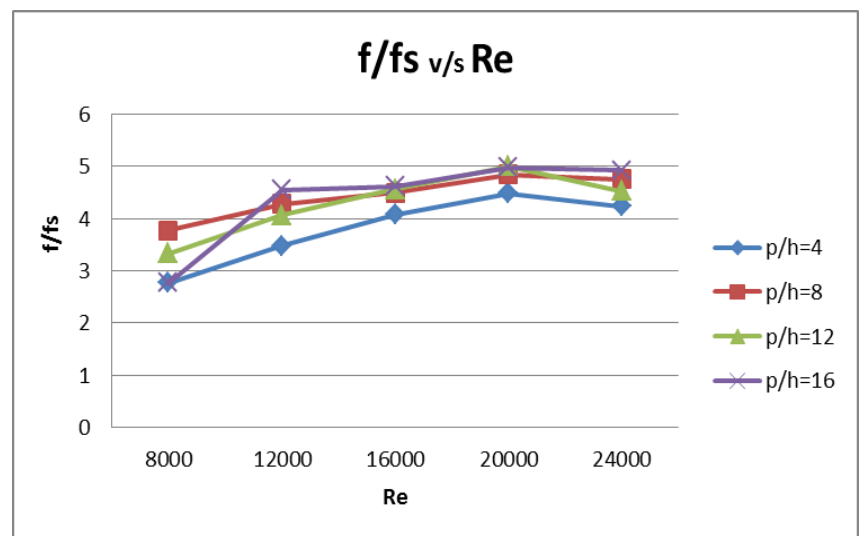

Fig 10: Variation of $\mathrm{f} / \mathrm{fs}$ with $\operatorname{Re}(\mathrm{AR}=3, \mathrm{~h}=7.5 \mathrm{~mm})$, Detachment $=4 \mathrm{~mm}$

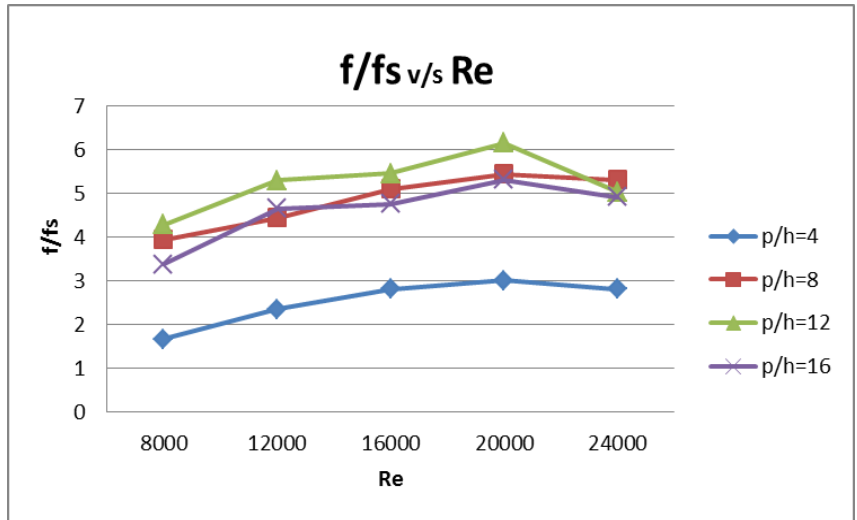

Fig 11: Variation of $\mathrm{f} / \mathrm{fs}$ with $\operatorname{Re}(A R=3.6, h=6 \mathrm{~mm})$, Detachment $=4 \mathrm{~mm}$

In fig 8 friction factor ratio for Reynolds number 20000is $7.20 \%$ time more than the friction factor ratio for Reynolds number8000 and at $\operatorname{Re} 20000$ to 240000 friction factor reducesdue to break down of vortices for pitch to height $(\mathrm{p} / \mathrm{h})$ 4. In fig 9 graph friction factor ratio for $\mathrm{Re} 24000$ is $9.3 \%$ time more than the friction factor for Re 8000 . In fig 10 graph friction factor ratio for Re 24000 is $8.76 \%$ more than the friction factor ratio of $\operatorname{Re} 8000$ for $(\mathrm{p} / \mathrm{h})$ 4.In fig 11 friction factor ratio for $\operatorname{Re} 24000$ is $7.9 \%$ more than the friction factor for $\operatorname{Re} 8000$, because if height increase friction factor ratio increase, the vortex generator top face is flat surface not a tip due to flat surface fiction factor will be more friction factor than tip surface.

\subsection{Variation of Aspect Ratio (Ar) with Friction}

\section{Factor Ratio (f/fs)}

Fig 12 to 15 shows the variation of friction factor ratio and aspect ratio (AR) for detached ribs with Reynolds number 8000 to 24000 and height $\mathrm{h}=16,12.5,7.5,6 \mathrm{~mm}$. If aspect ratio (AR) increase friction factor ratio (f/fs) decreases, $\mathrm{AR}=1.4$ has higher value than the remaining $\mathrm{AR} 1.8,3$ and 3.6 , because of the height of vortex generator, so when height increases friction factor ratio value also increases, vortex generator top plate is not a tip surface it has flat surface, for flat surface there will be better mixing of air flow in rectangular channel.

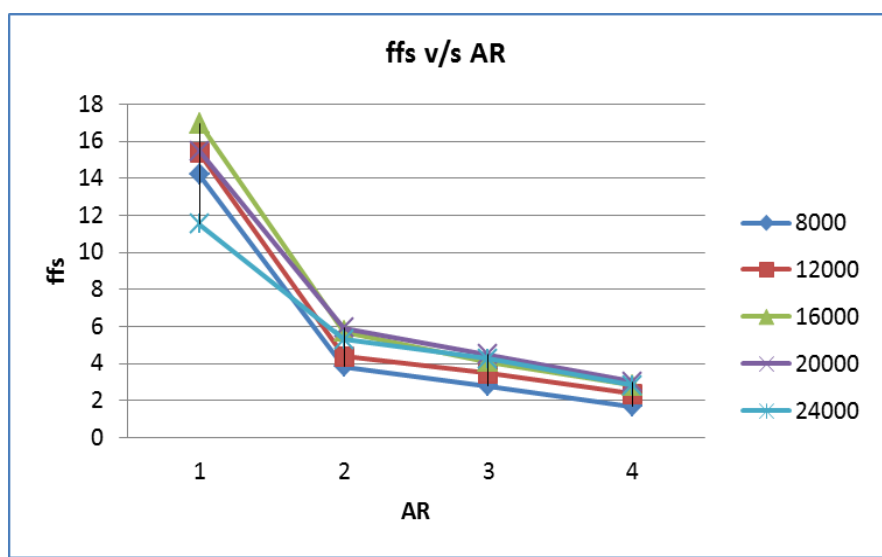

Fig 12: Variation of $f / f s$ with $A R(p=4 m m)$, Detachment $=4 \mathrm{~mm}$ 


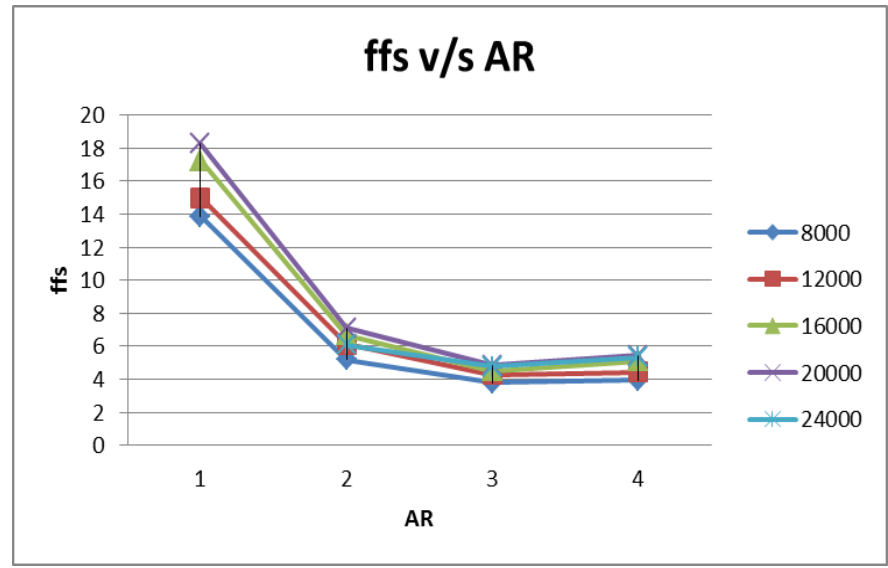

Fig.13: Variation of $\mathrm{f} / \mathrm{fs}$ with $\mathrm{AR}(\mathrm{p}=8 \mathrm{~mm})$, Detachment $=4 \mathrm{~mm}$

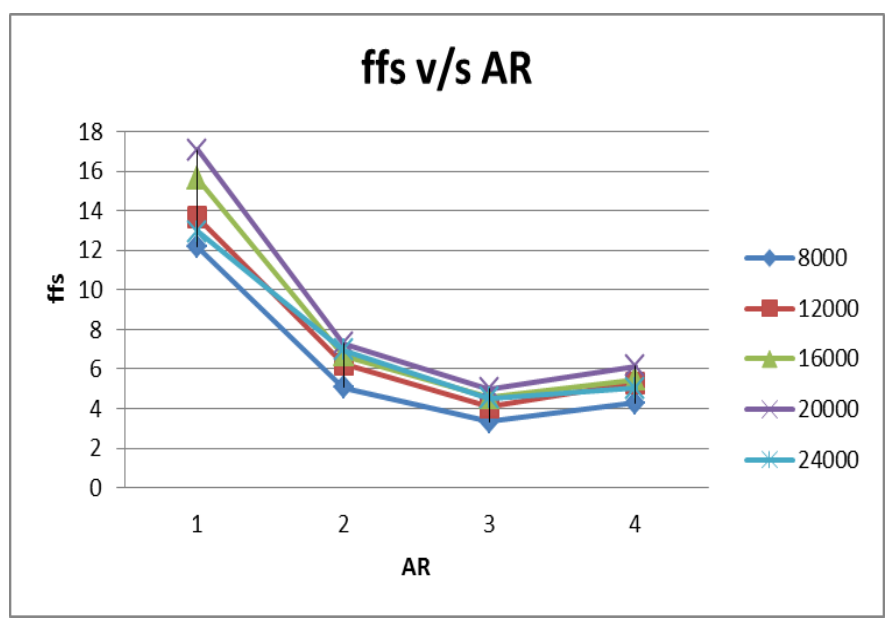

Fig 14: Variation of $\mathrm{f} / \mathrm{fs}$ on $\mathrm{AR}(\mathrm{p}=12 \mathrm{~mm})$, Detachment $=4 \mathrm{~mm}$

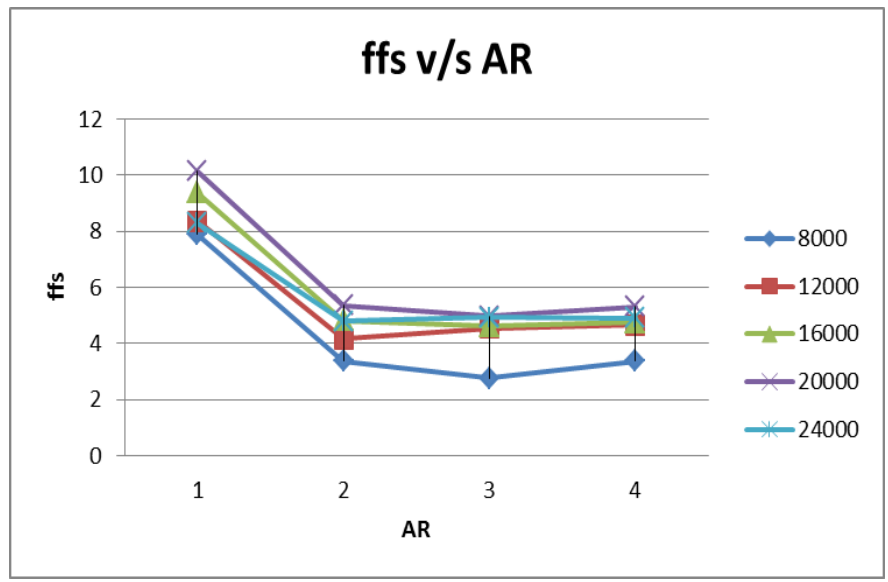

Fig 15: Variation of $\mathrm{f} / \mathrm{fs}$ on $\mathrm{AR}(\mathrm{p}=16 \mathrm{~mm})$, Detachment $=4 \mathrm{~mm}$

In fig 12 Friction factor ratio (f/fs) for aspect ratio (AR) 1.4 is $45.64 \%$ is lower than friction factor ratio $(\mathrm{f} / \mathrm{fs})$ for aspect ratio (AR) 3.6, for $\mathrm{Re}=16000$, because when height of vortex generator increase friction factor ratio will high value. In fig 13 Friction factor ratio (f/fs) for aspect ratio (AR) 1.8 is $57.75 \%$ lower than the friction factor ratio for aspect ratio (AR) 3.6for 8000 Reynolds number (Re), if pitch decreases friction factor also decrease because there will less blockage for that reason there will less mixing of air flow this results less pressure drop. In fig 14 Friction factor ratio for aspect ratio (AR) 3.6 is $80.72 \%$ lower than friction factor for aspect ratio (AR) 1.4 for Reynolds number (Re) 8000 and for $A R=1.4$. In fig 15 Friction factor ratio for aspect ratio(AR) 3.6 is $85.37 \%$ for friction factor ratio for aspect ratio (AR) 1.4.comparing from graphs 12 to 15 friction factor value is continuously decreases because pitch value increase, if distance between two adjacent vortex generator is more than there will be less disturbance or less friction in the channel and there will less mixing of air flow due to this there will be less pressure drop.

\section{CONCLUSION}

The following conclusions can be drawn from this work:

If pitch to height increase then friction factor ratio decrease, if pitch to height increase then friction factor ratio decrease by $28.98 \%$, because if pitch distance between two vortex generators increase their will be less friction or disturbance in the duct.

If Reynolds number increase friction factor ratio also increase because there will be better air mixing flow because of vortex generators, when Reynolds number is low, low velocity of fluid will have low air mixing, when Reynolds number increases, $8.34 \%$ time friction factor ratio also increase.

If height of vortex generator increases then friction factor ratio also increases, because it is depended upon dimension of duct and if height of vortex generator is half of duct then there will be greater friction factor ratio and if height of vortex generator is $(1 / 3)^{\mathrm{rd}}$ of duct then there will be lesser friction factor ratio.

If aspect ratio (AR) increases friction factor ratio decreases, when aspect ratio increase then friction factor ratio decreases by $80.03 \%$, because of the height of vortex generator and also the angle of attack, which is placed at $90^{\circ}$

\section{REFERENCES}

[1] PongjetPromvonge, "Heat transfer and pressure drop in a channel with multiple $60^{\circ} \mathrm{V}$-baffles" International Communications in Heat and Mass Transfer 37 (2010) 835-840.

[2] PongjetPromvonge, SompolSkullong, SutapatKwankaomeng, ChinarukThiangpong, "Heat transfer in square duct fitted diagonally with anglefinned tape- Part 1: Experimental study" International Communications in Heat and Mass Transfer 39 (2012) 617-624.

[3] MohitTaneji, SandeepNandal, ArpanManchanda, Ajay Agarwal "Exprimental study of convective heat transfer and thermal performance in the heat-sink channel with various geometrical configurations fins" (IJETT) vol. 4 page 2241-2246. 2013.

[4] AmnartBoonlai, WithadaJedsadaratanachai, PongjetPromvonge "Laminar periodic flow and heat 
transfer in square duct with30 end - trimmed rectangular winglet" KKU ENGINEERING JOUNRAL April- June 2013; 40(2): 139-146.

[5] AmnartBoonlai "Performance assessment and empirical correlation in a heat exchanger square duct with diagonal inserted generators" Forntiers in Heat and Mass Transfer(FHMT), 5, 8 (2014).

[6] TeerapatChompookham, ChinarukThinpong, SutapatKwankaomeng, PongjetPromvonge "Heat transfer augmentation in a wedge-ribbed channel winglet vortex generators" International Communication in Heat and Mass Transfer 37 (2010) 163-169.

[7] Chi-Chuan Wang, Jerry Lo, Yur-Tsai Lin, Min-Sheng Liu, "Flow visualization of wave-type vortex generators having inline fin-tube arrangement" International Journal of Heat and Mass Transfer 45 (2002) 1933-1944.

[8] Joardar A, Jacobi A.M. "Heat transfer enhancement by winglet-type vortex generator arrays in compact plainfin-and-tube heat exchangers" International journal of refrigeration 31 (2008) 87 - 97

[9] K. Yongsiri, P.Eiamsa-ard , K.Wongcharee , S.Eiamsaard "Augmented heat transfer in a turbulent channel

[10] AndallihTariq, K, Muralidar "Flow and heat transfer in the wake of a surface-mounted rib with a slit" Experiments in Fluids 37 (2004) 701-719.

[11] Alvaro Valencia, Marcela cid "Turbulent unsteady flow and heat transfer in channels with periodically mounted square bars" International Communication in Heat and Mass Transfer 45 (2002) 1661-1673.

[12] K.Arun and S.V.Prabhu "Effect of aspect ratio , channel orientation, rib pitch-to-height ratio, and number of ribbed walls on pressure drop characteristic in a rotating channel with detached ribs" International Journal of Rotating Machinery vol.2007 Article ID 72190, 11 pages.

[13] Hassan, Hemida, Sinisa,krajnovic "LES study of the influence of the vortex generators on cooling a surfacemounted cubes" International Issue in Emerging Technologies, THETA 1 , Cario, Eygpt , Jan 3-6 2007.

[14] G.V.Phadtare, Dr.A.A.Pawar, Dr.S.L.Borse, S.V.Channapattana "Experimental investigations of heat transfer enhancement in the tip of 180-degree bend of square duct with vortex generators" International Journal Engineering Science and Technology (IJEST) vol.5 No.07 July 2013 pages $1366-1374$.

[15] Yinxiao Zhan, Tae sean park "Effect of insulated oblique plates on heat transfer and recirculating flow in a channel" Journal of Applied Mathematics and Physics ,2014, 2, 405-410.

[16] J.M.Wu, W.Q. Tao "Numerical study on laminar convection heat transfer in a rectangular channel with longitudinal vortex generator. Part A: Verification of field synergy principle" International Communication in Heat and Mass Transfer 51 (2008) 1179-1191.

[17] Wisam Abed Kattea "An experimental study on the effect of shape and location of vortex generators ahead of a heat exchanger" Al-Khwarizmi Engineering Journal, vol.8, No 2, PP 12-19(2012).
[18] EknathKurhe, Sameer Bhosale "Thermal performance analysis of a circular tube using vortex rings at various angle and pitch ratio" International Journal for Research in Applied Science and Engineering Technology (IJRASET) Vol.2 Issue VIII, August 2014 pp 191-199.

\section{BIOGRAPHIES}

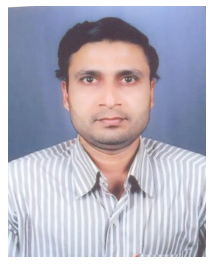

Myself Anand Kumar S Malipatil working at VTU as Assistant Professor .I have a teaching experience of 6 Years and I,am pursuing my Phd in heat transfer and fluid flow area.

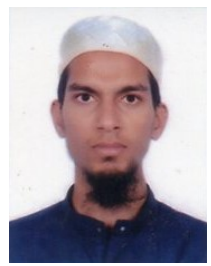

Abdul Rahman securing M.Tech degree in Thermal Power Engineering, VTU Ro/PG Kalaburagi and completed B.E in Mechanical Engg, and area of interest is "heat transfer and fluid flow". 